\title{
Sensorimotor circuitry involved in the higher brain control of coughing
}

\author{
Stuart B Mazzone ${ }^{1 *}$, Alice E McGovern ${ }^{1}$, Seung-Kwon Yang ${ }^{1}$, Ariel Woo' ${ }^{1}$, Simon Phipps ${ }^{1}$, Ayaka Ando ${ }^{1,2}$, \\ Jennifer Leech ${ }^{1,2}$ and Michael J Farrell ${ }^{2}$
}

\begin{abstract}
There is an overwhelming body of evidence to support the existence of higher brain circuitries involved in the sensory detection of airways irritation and the motor control of coughing. The concept that cough is purely a reflex response to airways irritation is now superseded by the recognition that perception of an urge-to-cough and altered behavioral modification of coughing are key elements of cough disorders associated with airways disease. Understanding the pathways by which airway sensory nerves ascend into the brain and the patterns of neural activation associated with airways irritation will undoubtedly provide new insights into disordered coughing. This brief review aims to explore our current understanding of higher order cough networks by summarizing data from recent neuroanatomical and functional studies in animals and humans. We provide evidence for the existence of distinct higher order network components involved in the discrimination of signals arising from the airways and the motor control of coughing. The identification of these network components provides a blueprint for future research and the development of targeted managements for cough and the urge-to-cough.
\end{abstract}

\section{John Widdicombe remembered}

In 2002, while holidaying in London, I (SBM) received a pleasant email invitation to join John and his wife Margaret for dinner in a little Italian restaurant owned by a family member. Over dinner John and I chatted about many things 'respiratory', including the complete absence (at the time) of any neurophysiological insights into the control of cough by supramedullary brain regions. John described his disappointment at several failed experiments with Abe Guz, trying to image brain responses during the urge-to-cough in humans. By the end of that night John had set me a friendly challenge, to move beyond the brainstem and tease apart the complexities of cough control in the higher brain. This short preface is to acknowledge John's support and encouragement for the work that is described below and to pay tribute to his immense contribution to the field. It has been an honor and a privilege for our team to contribute to this John Widdicombe memorial series, in memory of a truly inspirational respiratory physiologist.

\footnotetext{
* Correspondence: s.mazzone@uq.edu.au

'School of Biomedical Sciences, University of Queensland, St Lucia, Brisbane, QLD, Australia 4072

Full list of author information is available at the end of the article
}

\section{Evidence for higher brain involvement in coughing}

Over the past decade there has been a significant increase in research into cough neural pathways and this has provided respiratory researchers with new insights into the cough reflex as well as the cognitive and behavioral aspects of respiratory defensive responses mediated by sensory neural activation [reviewed in 1-5]. We have long suspected that higher brain neural pathways are involved in the perception of airway irritation and the behavioral modification of coughing, yet attempts to study this have only recently begun to appear in the scientific literature. However, we are now beginning to appreciate the very important role that higher brain circuits play in both the ongoing control of respiration as well as in manifestations of respiratory pathophysiology, particularly in the generation of symptoms associated with pulmonary diseases. This brief review will summarize studies from our group and others which are beginning to describe the identity and organization of the higher brain sensorimotor circuits that regulate coughing.

Cough is a motor act, and is characterized by reorganization of the central breathing pattern generator to produce the characteristic three phases of a typical cough 
(inspiration, compression and expiration). It can be evoked reflexively or enlisted voluntarily, indicating that multiple inputs can drive the final motor response [6,7]. Reflex cough is largely dependent upon vagal afferent inputs that are processed at the brainstem level [6,8-10]. Such reflex evoked coughing can be elicited from the airways under general anesthesia or in decerebrate animals suggesting that neural processing above the level of the brainstem is not essential for reflex coughing [6,8]. Thus, it seems likely that reflex cough represents the basic defensive mechanism for clearing the airways of an acute respiratory insult, ensuring that airway patency is maintained. Much of the primary afferent and brainstem processing network involved in reflex cough has been described in detail elsewhere (see references above) and is therefore not the subject of the present review. Voluntary cough and cough suppression, on the other hand, involve higher brain circuitries that are responsible for planning and initiating the motor act and for consciously controlling the final motor output to the muscles of respiration $[7,11]$. Furthermore, although reflex cough does not require suprapontine involvement, higher level regulatory mechanisms exist that can provide modulatory inputs to the basic brainstem reflex circuit [7].

In addition to higher brain descending pathways that regulate the motor act of coughing, it is now well established that higher order sensory pathways receive inputs from the airways and play an important role in generating cognitive sensory responses to airways irritation [12-14]. The urge-to-cough is a sensory experience that provides an awareness of the presence of an irritation in the upper airways and in turn drives the resultant desire to respond to that stimulus by coughing (to facilitate clearance of the offending irritant). Accordingly, the urgeto-cough can be considered one of several pulmonary sensory mechanisms that allows for the conscious perception of the operating conditions of the respiratory system and for the behavioral regulation of respiration in order to respond to changes in these conditions [2]. In this sense, cough driven by the urge-to-cough is clearly distinct from reflex coughing, in which the conscious behavioral component is minimal or non-existent. Given that it is becoming more widely accepted that chronic cough in disease has a significant behavioral component, it stands to reason that future therapeutic strategies for relieving excessive coughing will be underpinned by an understanding of the neural basis of the urge-to-cough.

\section{Suprapontine cough pathways}

Humans (and probably other mammals) can perceive, and to some extent localize, an irritation that is present in their airways. It is this perceptual awareness that results in the unpleasant sensations arising from the airways during irritation or inflammation (for example, the persistent laryngeal itch experienced during an upper respiratory viral infection), and ultimately drives the urge-to-cough [15]. Furthermore, humans upon voluntarily command can evoke or suppress a cough, or can have their coughs subconsciously modified by higher order brain processes involving placebo, anxiety or attentional tasks [7,16-18]. Taken together these observations support the existence of neural circuitry above the level of the reflex processing sites in the brainstem that receive inputs from the airways and provide descending control over, or in parallel to, the medullary cough pattern generator [7]. We have used a combination of functional brain imaging studies in humans and neuroanatomical tract tracing studies in rodents to identity and describe core components of this higher brain circuitry (Figure 1).

\section{Functional brain imaging experiments of the urge-to-cough in humans}

In 2007 our group published the first description of the neural substrates of the urge-to-cough in humans [13] and revealed the complexity of the distributed neural circuitry that detects and responds to airway irritations. In this study we performed functional brain imaging on ten healthy participants during inhalational challenge with a nebulized capsaicin solution, the concentration of which was titrated for each individual to produce a modest urge-to-cough without evoking reflex coughing. The results defined core network components that make up the higher brain sensorimotor control of cough including widespread cortical and subcortical activations that encompass sensory, motor, premotor and limbic structures. In a follow up study [12], we manipulated the intensity of subjects' urge-to-cough using graded capsaicin challenges, the results of which confirmed the basic core network described in our first study but also enabled us to dissect this distributed network into components (modules) that encode sensory, cognitive or motor responses (Figure 1).

The "sensory module" is composed of brain regions that receive (directly or via relay) ascending inputs originating from the airways and encodes either sensory discrimination (stimulus intensity and perception) or spatial discrimination (stimulus localization). Our data suggest that the primary somatosensory cortex and anterior insula play important roles in sensory discrimination whereas the posterior parietal cortex and dorsolateral prefrontal cortex are important for spatial discrimination [12]. These basic patterns of activation are not dissimilar to that described for other sensory modalities of somatic or visceral origin $[19,20]$. Interestingly, the magnitude of a delivered stimulus may not always be reflected in an individual's perception of the stimulus magnitude. Indeed, other cortical functions including emotion, attentional 


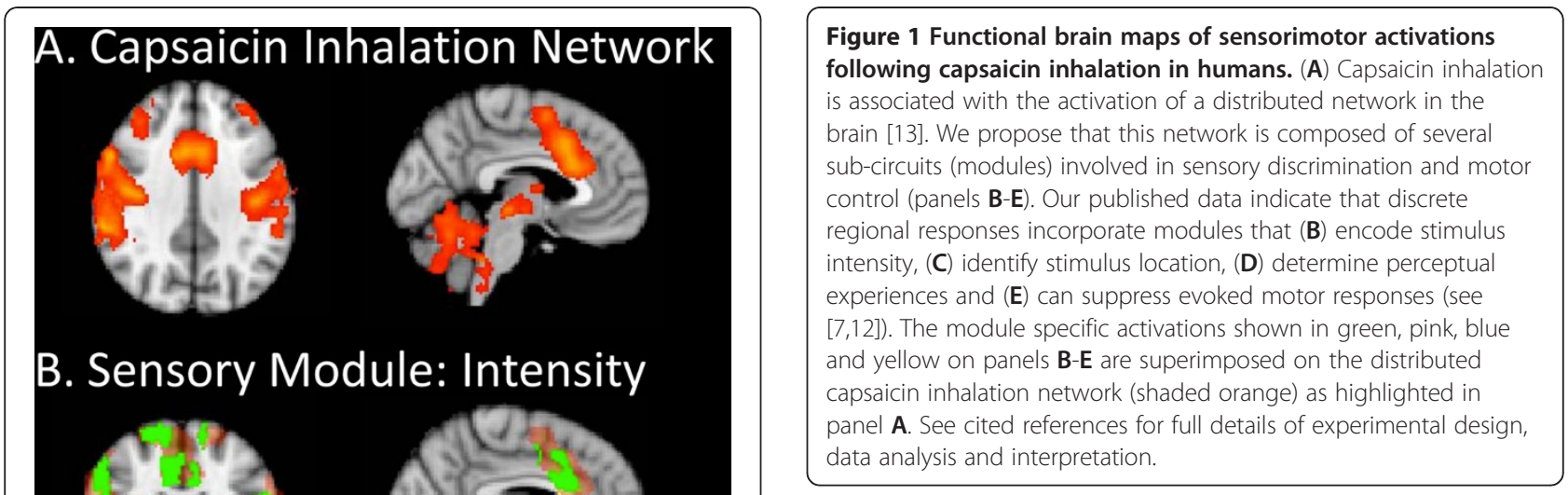

focus and alertness can influence the perception of stimulus intensity $[17,21,22]$. By taking advantage of this, we have noted distinctions between those brain regions (e.g., the anterior insula) that faithfully activate in a stimulusdependent fashion versus other regions (e.g., primary sensory cortex) where the activation correlates with how intense subjects perceive the stimulus to be $[10,12]$. We interpret this as evidence for distinct components of the sensory discrimination network, one of which decodes stimulus intensity and the other incorporates this information with other competing central processing to generate the magnitude of the perceivable urge-to-cough. Urge-to-cough experimental paradigms, like other examples of experiments employing noxious stimuli, recruit orbitofrontal cortex, cingulate cortex and other limbic regions (the "cognitive module") which are likely involved in shaping an individual's affective responses to airway irritation $[23,24]$. Less is known about the affective processing associated with airways irritation. Of interest, however is that individuals with respiratory disorders such as asthma or chronic cough have a significantly increased risk of developing mood and anxiety disorders, and it seems likely that this would be reflected in altered activity of the network components comprising this cognitive module [25-28].

Many of the network components identified in our urge-to-cough fMRI studies include regions that are activated in other sensorimotor paradigms, including noxious stimulation of cutaneous tissues and other visceral sensory modalities (studies of pain, dyspnea or esophageal distension, for example) [10,29-32]. This suggests the existence of a core network in the brain that plays a generalized role in interoceptive processing. However, given that each of these sensory stimuli enlist distinct sensations and different behavioral responses, the core network must be either topographically arranged or be supplemented by additional neural components that allow for tissue specific responses. Identifying such functional elements within this network is a significant challenge. 


\section{Functional brain imaging experiments of cough motor control in humans}

Given that a primary purpose of the urge-to-cough is as a sensory experience to promote behavioral modifications in respiratory control (i.e., to facilitate or suppress coughing), it is therefore of interest to understand the higher brain circuitry responsible for voluntary control of cough. We and others have performed studies of voluntary cough, capsaicin-evoked cough and/ or cough suppression during capsaicin inhalation to define the components of the cough "motor module" [7,11]. Voluntary cough is associated with activity in a number of regions including the sensorimotor cortex, supplementary motor area and cerebellum. A distinction can be made between voluntary cough and reflex cough by the pattern of activation in the posterior insula and posterior cingulate cortices that is characteristic of capsaicinevoked cough, indicating that the brain activity associated with reflex cough is not simply a function of that produced by voluntary cough and airways irritation [7]. The distinction between reflex and voluntary cough is also apparent at the brainstem level. Thus, whereas reflex cough is associated with medullary activation, there appears to be minimal brainstem involvement associated with voluntary coughing [7]. We have interpreted this finding as evidence that corticospinal pathways may be responsible for voluntary coughing, rather than cortical inputs into the medullary respiratory circuit per se [33]. The suppression of irritant evoked coughing is also associated with a unique pattern of brain activity, including an involvement of the anterior insula, supplementary motor area, motor cingulate cortex and right inferior frontal gyrus $[7,12]$. Interestingly, the right inferior frontal gyrus, along with the pre-supplementary motor area, prefrontal cortex, subthlamamic nucleus and basal ganglia, comprises an inhibitory network that has been shown to be involved in response inhibition during a variety of motor suppression paradigms $[34,35]$. Comparable activations are also associated with volitional breath holding, supporting the notion that this circuitry is intimately involved in respiratory and cough suppression [36].

\section{Neuroanatomical organization of ascending airway afferent pathways}

The functional brain imaging studies described above provide a 'snapshot' of the brain regions activated by a given respiratory task. However, they do not necessarily detail the pathways via which these regions are interconnected. We have begun to assess the anatomy of the ascending circuitry that arises from the airways and provides input to the cortex using a novel viral neural tracing system. To do this, we have developed recombinant herpes simplex viruses (HSV1) strain H129 that genetically encode for the production of green or red fluorescent proteins in infected cells $[37,38]$. HSV1 H129 is unique in that it is one of only a few viruses that have the ability to infect neurons and pass between synaptically connected neurons in the anterograde direction $[37,39]$. This property makes the H129 virus ideal for tracing sensory neural pathways and following their connectivity deep into the brain.

Using recombinant HSV1 H129 in rodents we have shown that tracheal afferent neurons terminate in two brainstem nuclei, the nucleus of the solitary tract and the trigeminal/ paratrigeminal nuclei (Figure 2). Whilst previous studies have documented in some detail tracheal afferent terminations in the nucleus of the solitary tract $[9,40]$, there haven't been any previous reports of tracheal sensory neurons projecting directly to the trigeminal regions of the brainstem. At present it is unclear of the functional significance of vagal afferent innervation of trigeminal neurons nor is it clear whether it is a specific subset of airway afferent nerves that projects to the trigeminal nucleus or if all airway afferents provide collateral terminals to this

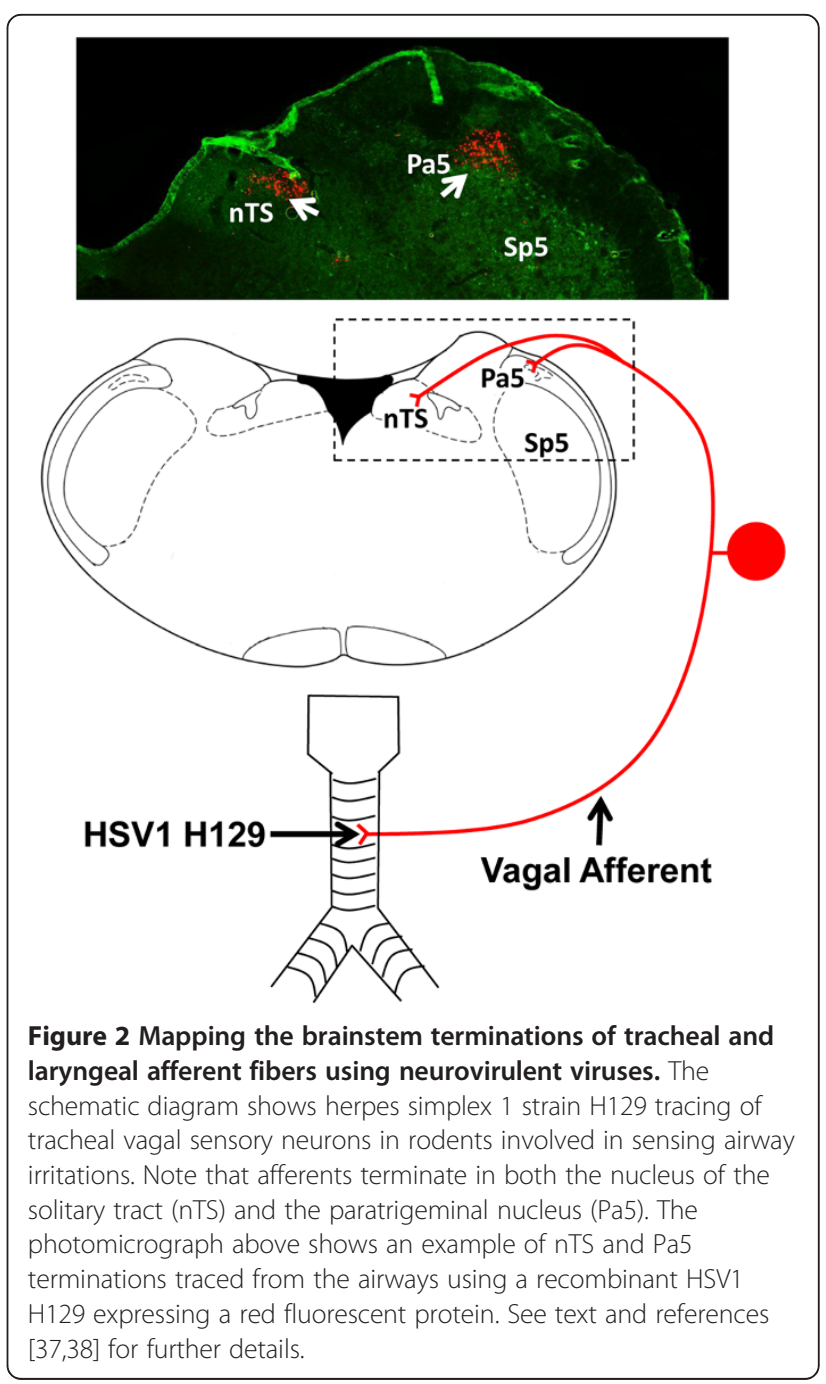


brainstem region. However our data would suggest that a significant population of trigeminal neurons may relay airway afferent input to thalamic loci, likely via well described trigeminothalamic tracts [37]. Indeed, one population of thalamic relay neurons is located in the ventral posterior nuclei, but not in the visceral sector (the ventral posteriolateral parvicellular thalamus as defined by [41]), suggesting that upper airway ascending pathways more resemble those of cutaneous afferents rather than other vagal afferents. These neurons in turn project onto layer IV and V primary and secondary somatosensory cortices, which again are in distinct loci when compared to the cortical terminations described for other visceral and vagal systems [41,42] (Figure 3). We speculate that trigeminothalamocortical pathways may prove to be an important circuitry encoding perceptual awareness of airway irritation, and hence in the generation of the urge-to-cough. A

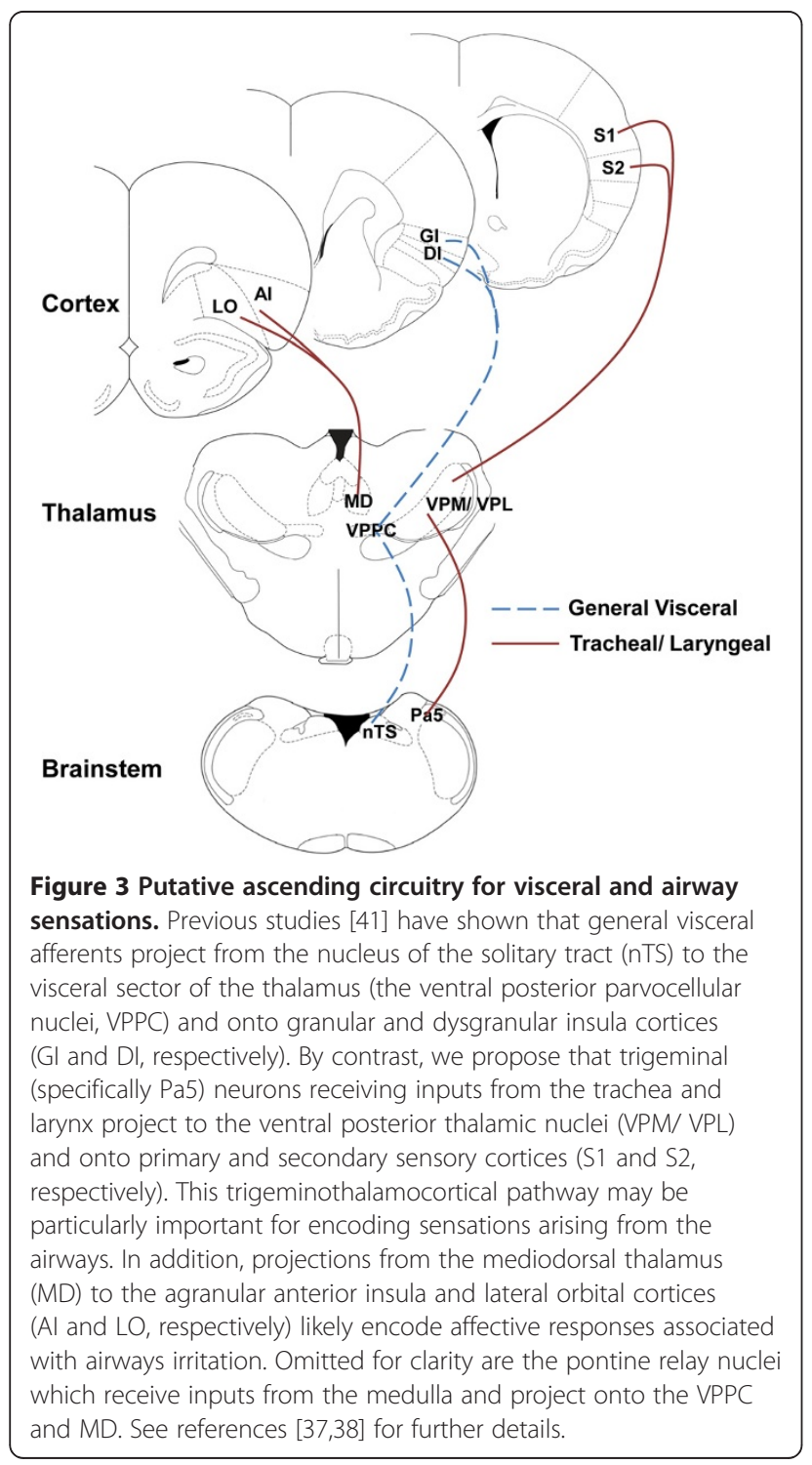

second group of thalamic relay neurons is located in the dorsomedial thalamus and in turn send projections to limbic regions of the brain including the anterior insula and orbital cortices [37,38]. Recently Davenport and colleagues [43] reported that tracheal occlusion in rats leads to altered gene expression in the medial thalamus and suggested that this was due to inputs from respiratory mechanoreceptors. These data support our assertion that the medial thalamus is also involved in encoding airway sensory input, although it seems likely that this relates to affective processing relating to anxiety, fear and arousal involving the limbic brain as opposed to sensory perception or discrimination per se $[37,38,43]$. Importantly, these basic anatomic circuits identified in rodents are in close agreement with our functional brain maps generated from fMRI in humans.

\section{Concluding remarks}

There is still much to learn about the basic organization of the suprapontine brain circuits that detect and respond to airways irritation. Our understanding of the anatomy, physiology and pharmacology of these circuits is in its infancy. Furthermore, whether patients with a chronic cough disorder display functional changes in these central neural processing sites is not known. We propose that aberrant cough associated with airways disease may indeed be associated with abnormal processing in the brain networks involved in sensory perception of airways irritation and/or motor suppression of cough. If correct, this would provide an alternative therapeutic goal for treating chronic cough. Restoration of normal central processing could allow for cough normalization in disease without disrupting either voluntary or reflexive cough, which are essential for the protection of the airways during occasions of acute insult.

\section{Competing interests}

The authors declare that they have no competing interests.

\section{Authors' contribution}

AM, SY, AW, SP carried out the animal tracing studies while AA and JL carried out the human imaging studies described in the manuscript. SM and MF analysed and interpreted the data. SM drafted the manuscript. All authors read and approved the final manuscript.

\section{Funding}

The data described in this manuscript was funded by grants (1025589, 1042528) to SBM and MF from the National Health and Medical Research Council of Australia.

\section{Author details}

${ }^{1}$ School of Biomedical Sciences, University of Queensland, St Lucia, Brisbane, QLD, Australia 4072. ${ }^{2}$ The Florey Institute of Neuroscience and Mental Health, Melbourne, VIC, Australia 3010. 


\section{References}

1. Canning BJ: Functional implications of the multiple afferent pathways regulating cough. Pulm Pharmacol Ther 2011, 24(3):295-299.

2. Davenport PW, Vovk A: Cortical and subcortical central neural pathways in respiratory sensations. Respir Physiol Neurobiol 2009, 167(1):72-86.

3. Mazzone SB, McGovern AE, Cole $L$, Farrell MJ: Central nervous system control of cough: pharmacological implications. Curr Opin Pharmacol 2011, 11(3):265-271.

4. Shannon R, Baekey DM, Morris KF, Nuding SC, Segers LS, Lindsey BG: Production of reflex cough by brainstem respiratory networks. Pulm Pharmacol Ther 2004, 17(6):369-376.

5. Van den Bergh O, Van Diest I, Dupont L, Davenport PW: On the psychology of cough. Lung 2012, 190(1):55-61.

6. Canning BJ, Mazzone SB, Meeker SN, Mori N, Reynolds SM, Undem BJ: Identification of the tracheal and laryngeal afferent neurones mediating cough in anaesthetized guinea-pigs. J Physiol 2004, 557(Pt 2):543-558.

7. Mazzone SB, Cole LJ, Ando A, Egan GF, Farrell MJ: Investigation of the neural control of cough and cough suppression in humans using functional brain imaging. J Neurosci 2011, 31(8):2948-2958.

8. Baekey DM, Morris KF, Gestreau C, Li Z, Lindsey BG, Shannon R: Medullary respiratory neurones and control of laryngeal motoneurones during fictive eupnoea and cough in the cat. J Physiol 2001, 534(Pt. 2):565-581.

9. Canning BJ, Mori N: An essential component to brainstem cough gating identified in anesthetized guinea pigs. FASEB J 2010, 24(10):3916-3926.

10. Mazzone SB, McGovern AE, Koo K, Farrell MJ: Mapping supramedullary pathways involved in cough using functional brain imaging: comparison with pain. Pulm Pharmacol Ther 2009, 22(2):90-96.

11. Simonyan K, Saad ZS, Loucks TM, Poletto CJ, Ludlow CL: Functional neuroanatomy of human voluntary cough and sniff production. Neuroimage 2007, 37(2):401-409.

12. Farrell MJ, Cole LJ, Chiapoco D, Egan GF, Mazzone SB: Neural correlates coding stimulus level and perception of capsaicin-evoked urge-to-cough in humans. Neuroimage 2012, 61(4):1324-1335.

13. Mazzone SB, McLennan L, McGovern AE, Egan GF, Farrell MJ: Representation of capsaicin-evoked urge-to-cough in the human brain using functional magnetic resonance imaging. Am J Respir Crit Care Med 2007, 176(4):327-332.

14. Pate KM, Davenport PW: Tracheal occlusions evoke respiratory load compensation and neural activation in anesthetized rats. J Appl Physiol 2012, 112(3):435-442.

15. Vertigan $A E$, Gibson PG: Chronic refractory cough as a sensory neuropathy: evidence from a reinterpretation of cough triggers. J Voice 2011, 25(5):596-601.

16. Davenport PW: Clinical cough I: the urge-to-cough: a respiratory sensation. Handb Exp Pharmacol 2009, 187:263-276.

17. Davenport PW, Vovk A, Duke RK, Bolser DC, Robertson E: The urge-to -cough and cough motor response modulation by the central effects of nicotine. Pulm Pharmacol Ther 2009, 22(2):82-89.

18. Hegland KW, Bolser DC, Davenport PW: Volitional control of reflex cough. J Appl Physiol 2012, 113(1):39-46.

19. Olausson H, Charron J, Marchand S, Villemure C, Strigo IA, Bushnell MC: Feelings of warmth correlate with neural activity in right anterior insular cortex. Neurosci Lett 2005, 389(1):1-5.

20. Oshiro Y, Quevedo AS, McHaffie JG, Kraft RA, Coghill RC: Brain mechanisms supporting discrimination of sensory features of pain: a new model. J Neurosci 2009, 29(47):14924-14931.

21. Leech J, Mazzone SB, Farrell MJ: The effect of placebo conditioning on capsaicin-evoked urge-to-cough. Chest 2012, 142(4):951-957.

22. Hölzl R, Erasmus LP, Möltner A: Detection, discrimination and sensation of visceral stimuli. Biol Psychol 1996, 42(1-2):199-214.

23. Critchley HD, Wiens S, Rotshtein P, Ohman A, Dolan RJ: Neural systems supporting interoceptive awareness. Nat Neurosci 2004, 7(2):189-195.

24. Craig AD: How do you feel-now? The anterior insula and human awareness. Nat Rev Neurosci 2009, 10(1):59-70.

25. Dicpinigaitis PV, Tso R, Banauch G: Prevalence of depressive symptoms among patients with chronic cough. Chest 2006, 130(6):1839-1843.

26. McGarvey LP, Carton C, Gamble LA, Heaney LG, Shepherd R, Ennis M, MacMahon J: Prevalence of psychomorbidity among patients with chronic cough. Cough 2006, 2:4.

27. Rosenkranz MA, Busse WW, Johnstone T, Swenson CA, Crisafi GM, Jackson MM, Bosch JA, Sheridan JF, Davidson RJ: Neural circuitry underlying the interaction between emotion and asthma symptom exacerbation. Proc Natl Acad Sci USA 2005, 102(37):13319-13324.

28. Young EC, Brammer C, Owen E, Brown N, Lowe J, Johnson C, Calam R, Jones S, Woodcock A, Smith JA: The effect of mindfulness meditation on cough reflex sensitivity. Thorax 2009, 64(11):993-998.

29. Coen SJ, Gregory LJ, Yáqüez L, Amaro E Jr, Brammer M, Williams SC, Aziz Q: Reproducibility of human brain activity evoked by esophageal stimulation using functional magnetic resonance imaging. Am J Physiol Gastrointest Liver Physiol 2007, 293(1):G188-G197.

30. McKay LC, Critchley HD, Murphy K, Frackowiak RS, Corfield DR: Sub-cortical and brainstem sites associated with chemo-stimulated increases in ventilation in humans. Neuroimage 2010, 49(3):2526-2535.

31. Peiffer C, Poline JB, Thivard L, Aubier M, Samson Y: Neural substrates for the perception of acutely induced dyspnea. Am J Respir Crit Care Med 2001, 163(4):951-957.

32. von Leupoldt A, Sommer T, Kegat S, Baumann HJ, Klose H, Dahme B, Büchel C: Dyspnea and pain share emotion-related brain network. Neuroimage 2009, 48(1):200-206.

33. Corfield DR, Murphy K, Guz A: Does the motor cortical control of the diaphragm 'bypass' the brain stem respiratory centres in man? Respir Physiol 1998, 114(2):109-117.

34. Chikazoe J: Localizing performance of go/no-go tasks to prefrontal cortical subregions. Curr Opin Psychiatry 2010, 23(3):267-272.

35. Simmonds DJ, Pekar JJ, Mostofsky SH: Meta-analysis of Go/No-go tasks demonstrating that $\mathrm{FMRI}$ activation associated with response inhibition is task-dependent. Neuropsychologia 2008, 46(1):224-232.

36. McKay LC, Adams L, Frackowiak RS, Corfield DR: A bilateral cortico-bulbar network associated with breath holding in humans, determined by functional magnetic resonance imaging. Neuroimage 2008, 40(4):1824-1832.

37. McGovern AE, Davis-Poynter N, Farrell MJ, Mazzone SB: Transneuronal tracing of airways-related sensory circuitry using herpes simplex virus 1 , strain H129. Neuroscience 2012, 207:148-166.

38. McGovern AE, Davis-Poynter N, Rakoczy J, Phipps S, Simmons DG, Mazzone SB: Anterograde neuronal circuit tracing using a genetically modified herpes simplex virus expressing EGFP. J Neurosci Methods 2012, 209(1):158-167.

39. Barnett EM, Evans GD, Sun N, Perlman S, Cassell MD: Anterograde tracing of trigeminal afferent pathways from the murine tooth pulp to cortex using herpes simplex virus type 1. J Neurosci 1995, 15(4):2972-2984.

40. Mazzone SB, Canning BJ: Synergistic interactions between airway afferent nerve subtypes mediating reflex bronchospasm in guinea pigs. Am J Physiol Regul Integr Comp Physiol 2002, 283(1):R86-R98.

41. Cechetto DF, Saper CB: Evidence for a viscerotopic sensory representation in the cortex and thalamus in the rat. J Comp Neurol 1987, 262(1):27-45.

42. Allen GV, Saper CB, Hurley KM, Cechetto DF: Organization of visceral and limbic connections in the insular cortex of the rat. J Comp Neurol 1991, 311(1):1-16

43. Bernhardt V, Garcia-Reyero N, Vovk A, Denslow N, Davenport PW: Tracheal occlusion modulates the gene expression profile of the medial thalamus in anesthetized rats. J Appl Physiol 2011, 111(1):117-124.

doi:10.1186/1745-9974-9-7

Cite this article as: Mazzone et al.: Sensorimotor circuitry involved in the higher brain control of coughing. Cough 2013 9:7. 